NANA GENG, Ph.D. student ${ }^{1}$

(Corresponding Author)

E-mail: shiyu0618@163.com

YONG ZHANG, Ph.D. ${ }^{1}$

E-mail: zhangyong@seu.edu.cn

YIXIANG SUN, Ph.D. student ${ }^{2}$

E-mail: sunyixiang@nuaa.edu.cn

1 Southeast University

Sipailou 2, Nanjing, Jiangsu, China

2 Nanjing University of Aeronautics and Astronautics

Jiangjun road 29, Nanjing, Jiangsu, China
Traffic Planning

Preliminary Communication

Submitted: 27 Feb. 2017

Accepted: 24 Nov. 2017

\title{
A COORDINATING STRATEGY FOR BIOFUEL SUPPLY CHAIN UNDER DISTURBANCE USING REVENUE SHARING CONTRACT APPROACH
}

\begin{abstract}
Biofuel is considered to be an important alternative energy in the future transportation. Its development is supported by the rest of the world. However, biofuel industry development is still very slow. From the previous research it is known that the supply chain coordination and other problems need to be solved to promote the supply chain ability. This paper studies biodiesel supply chain coordination problem from the view of disturbance management. It gives a disturbed coordination strategy which contains the optimal order quantity and the contract parameters. This paper has then verified the disturbed coordination strategy through using the actual data of Jiangsu Yueda Kate New Energy Co. $L t d$. The result shows that when the market demand and the recovery cost are simultaneously disturbed, the coordination can make the biodiesel supply chain robust and the new strategy under the revenue sharing contract is better than the original one.
\end{abstract}

\section{KEY WORDS}

waste cooking oil; carbon emissions; disturbance; revenue sharing contract; biofuel supply chain;

\section{BACKGROUND}

Growing oil consumption has not only led to the potential energy security risks, but also to serious environmental pollution problems. The International Energy Agency and other departments vigorously encouraged the use of biofuel as an alternative energy to slow down the use of oil. They pointed out that the proportion of biofuel consumption in the transport sector is expected to increase from the current $2 \%$ to $27 \%$ in 2050 , and bring about $20 \%$ reduction in carbon emissions in the transport sector per year [1]. Currently, biofuel is divided into bioethanol and biodiesel. Since biodiesel is used more in buses and trucks than bioethanol and its supply chain being relatively mature, this paper has chosen biodiesel as the research object. Biomass cost which accounts for $75 \%-80 \%$ of the raw material cost is a major problem in the whole supply chain [2], while waste cooking oil which has a lower cost has been widely considered by the society. In the biodiesel industry the developing policy, it has been pointed out that a sustainable supply system needs to be urgently established. The system can use waste oil as the basic raw material and supplemented by non-edible herbaceous oil [3]. It also suggests regulating the production and application of biodiesel and building waste oil resource utilization channels. The biodiesel supply chain is mainly comprised of three main components: waste edible oil recycling station, biodiesel refinery factory, and biodiesel distributor. The biodiesel supply chain operation process is shown in the following: the recycling station collects waste edible oil and sells it to the refinery factory; the refinery factory uses it as raw material for biodiesel production and purification; then they sell the biodiesel product to all levels of distributors in the form of wholesale. Finally, the distributor sells the biodiesel to consumers in the retail sales.

As we all know, biofuel as an alternative energy, the terminal use can indeed reduce carbon emissions, but if the environment is disturbed, the recycling station, refinery factory and distributor may be coordinated in improper activities and the emission reduction effect would be counterproductive. Therefore, how to coordinate this special product supply chain to deal with the disturbance is an urgent issue. This paper uses the revenue sharing contract to realize the coordination of the three-echelon supply chain which is composed of a recycling station, biodiesel refinery factory and biodiesel distributor, and give the optimal order quantity and contract parameter condition of supply chain. Then, considering the market demand and production cost disturbance situation, the paper gives the 
biodiesel three-echelon supply chain coping strategies. Finally, the case of a biodiesel company in China is used to discuss the impact of the original strategy and the new strategy on the supply chain profit and production plan.

\section{LITERATURE REVIEW}

In the past, most part of literature has dealt with the coordination of two-echelon supply chain system [4], which is composed of suppliers - manufacturers $[5,6]$, manufacturers - distributors $[7,8]$ and distributors - retailers [9]. In practice, the supply chain is usually composed of more than two entities, and the multi-echelon supply chain is more common. However, the results of the study for three-echelon supply chain coordination are still rare. Munson and Rosenblatt [10] analysed the coordination effect of the quantity discount contract on the three-echelon supply chain. On the basis of their research, Hu and Wang [11] considered the randomness of the demand and discussed the impact of emergency on the three-echelon supply chain. From the aspect of game theory, Modak et al. [12] explored the channel coordination and profit division issues of a manufacturer - distributer - duopolistic retailers supply chain for a product where the manufacturer supplies a lot size of the product that contains a random portion of imperfect quality item. Panda et al. [13] studied the disposal cost sharing and bargaining for coordination and profit division in a three-echelon supply chain. Govindan and Popiuc [14] took the computer industry as an example and designed a revenue sharing contract to achieve risk sharing to coordinate the three-level supply chain system. At present, the more commonly used supply chain contracts are Wholesale Price Contract, Return Policy, Quantity Flexibility Contract, Revenue Sharing Contract, Profit Sharing Contract, Rebate and Penalty Contract.This paper has chosen the approach of Profit Sharing Contract for the following reason: From the direct distribution of the supply chain profit mechanism, supply chain members can more clearly see the effect of profit growth and the benefit distribution process is more intuitive and reliable. It is relatively easy to make the parties reach a consensus and actively support the development and implementation of the contracts. This paper studies the coordination of the three-echelon supply chain system, which is composed of the special recycling station - refinery factory - distributor. Nonetheless, this paper is different from the previous studies.

Firstly, the previous research on the disturbance of biofuel supply chain was mainly from the aspect of optimization modelling and the result is only to solve the problem of the location, transportation and storage of its refinery factory $[15,16,17]$ in order to enhance the robustness of the supply chain. Although there are many papers that have studied supply chain coordination strategies from the perspective of economy and perturbations, the research on the supply chain coordination strategies for biodiesel as a particular product is rare. In this paper, the biodiesel supply chain coordination strategy will take into account the economics, environment and production deterioration factors. Unlike the previous uncertainty in biodiesel research [18, $19,20]$, this paper has selected two factors, market demand and recycling cost which have great influence on the supply chain, and studies the coordination of the biodiesel supply chain in case of their simultaneous disturbance.

Secondly, the achievement of supply chain coordination is often manifested in the benefit improvement in the entire supply chain which is often considered only from the economic factors [21, 22, 23]. But actually, biodiesel supply chain, which is different from other products, needs to consider its situation of carbon emissions and waste oil recycling [24, 25, 26]. In this paper, the impact on supply chain profit of common costs, cost of carbon emissions and surplus product residuals has been considered.

Thirdly, the previous study analysed the three-echelon supply chain coordination, either from the impact of disturbance [27, 28], or only from supply chain revenue sharing contract [29,30]. This paper considers both of them and analyses the revenue sharing contract of supply chain under the disturbance, and designs the contract mechanism between the recycling station, the refinery factory and the distributor. It also discusses the setting of contract parameters to improve the performance of the biodiesel three-echelon supply chain.

\section{PROBLEM DESCRIPTION}

As shown in Figure 1, the recycling station does not deal directly with the distributor, but the profit of the recycling station is influenced by the pricing decision of the distributor. The recycling station can indirectly affect the distributor through the refinery factory. In the deterministic model, this paper uses the revenue sharing contract to realize the coordination of the biodiesel supply chain. At the same time, it is assumed that the recycling station, refinery factory and distributor are risk-neutral and completely rational, that is, they make decisions based on the principle of maximizing their own expected profit. Moreover, it is assumed that the information is complete, that is, they know their own and each other's cost structure, revenue function, etc., and can accurately predict the market demand. Prior to the start of the sale, the distributor made the optimal order quantity according to the revenue sharing contract, then the refinery factory and the recycling station arranged the production plan. However, the occurrence of uncertain events led to changes in the 


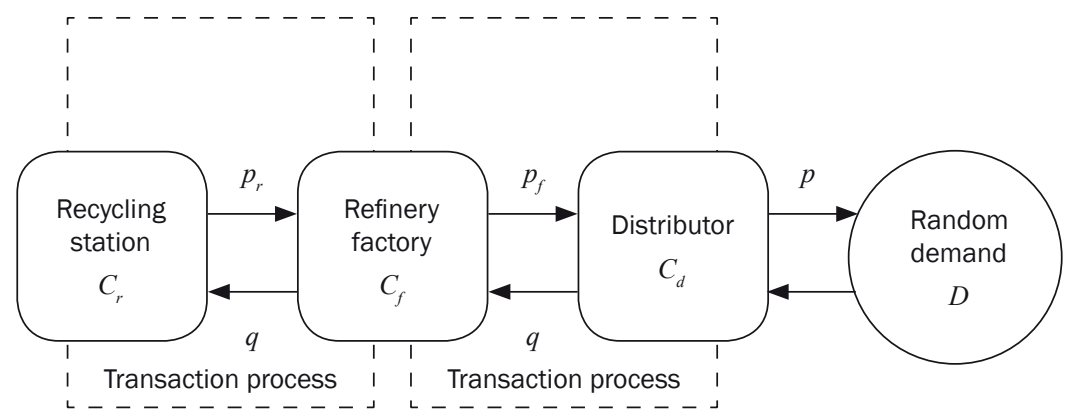

Figure 1 - Biodiesel three-echelon supply chain structure

market demand faced by the distributor and changes in the recycling cost of the recycling station. The two changes occurred at the same time. At this point, the initial plan may be broken; what is then the impact of the disturbance on the members of the biodiesel supply chain? How to harmonize these members under the disturbance of the biodiesel supply chain? These became the key problems to be solved by this paper.

\section{BIODIESEL SUPPLY CHAIN MODEL UNDER THE DETERMINISTIC SITUATION}

\subsection{Symbol setting}

Biodiesel supply chain is a three-echelon supply chain, which is composed of a recycling station, a refinery factory and a distributor. The distributor faces the stochastic demand. The three-node enterprises utilize the revenue sharing contract to achieve coordination. $q \quad$ - order quantity of the distributor; $p \quad-$ the retail price of biodiesel. It is a fixed price which is formed by the market competition;

$e_{d} \quad$ - carbon emission change cost of the distributor; which is caused by out-of-stock;

$e_{f} \quad$ - carbon emission change cost of the refinery factory, which is caused by out-of-stock;

$e_{r} \quad$ - carbon emission change cost of the recycling station, which is caused by out-of-stock;

$e=e_{d}+e_{f}+e_{r} \quad$ - total carbon emissions cost per unit product for the entire supply chain;

$c_{d} \quad$ - marginal cost of the distributor;

$c_{f} \quad-$ marginal production cost of the refinery factory;

$c_{r} \quad$ - marginal recovery cost of the recycling station;

$c=c_{d}+c_{f}+c_{r}<p$ - total cost per unit product for the entire supply chain;

$p_{f} \quad$ - the price which refinery factory provides to the distributor;
$p_{r}$
- the price which recycling station provides to the refinery factory;
$w \quad$ - the deterioration cost per unit
product, $w<c$;
$\theta_{1}, \theta_{2} \quad$ - interest distribution coefficient of the two supply chain nodes;
D - the stochastic demand faced by the distributor.

\subsection{Model building}

Suppose the density function of $D$ is $f(x)$, the distribution function is $F(x)$. Meet the conditions: $\mathrm{F}$ is differentiable and strictly increasing; $F(0)=0, \bar{F}(x)=1-F(x)$, $\mu=E(D)$ is the expected demand.

On the basis of the above assumptions, the expected sales volume can be obtained:

$$
\begin{aligned}
S(q)= & E[\min (q, D)]=q(1-F(q))+ \\
& +\int_{0}^{q} x f(x) d x=q-\int_{0}^{q} F(x) d x
\end{aligned}
$$

Expected remaining quantity:

$$
I(q)=E[\max (q-D, 0)] q-S(q)
$$

Expected shortage quantity:

$$
L(q)=E[\max (D-q, o)]=\mu-S(q)
$$

Expected profit of supply chain

$$
\pi(q)=(p+w+e) S(q)-(c+w) q-e \mu
$$

\subsection{Biodiesel supply chain coordination under the deterministic situation}

The coordination adopts the revenue sharing contract theory. The deterioration cost of surplus products and carbon emission changing cost are also considered, which is led by short supply of the distributor. The biodiesel supply chain operates as follows: first of all, the nodes in the supply chain predict demand $D$ faced by the distributor and get the distribution function F; then the distributor orders $q$ products from the refinery factory at the price of $p_{f}$; after obtaining the order of the distributor, the refinery factory begins to 
order $q$ products at the wholesale price $p_{r}$; finally, the recycling station arranges the production plan according to the order of the refinery factory. The distributor retains $\theta_{1}$ proportion of their income, and gives the $1-\theta_{1}$ proportion of the total income to the refinery factory. The refinery factory retains $\theta_{2}$ proportion of its income and gives the $1-\theta_{2}$ proportion of the total income to the recycling station, $\theta_{1}, \theta_{2} \in[0,1]$.

From the above process, it can be calculated that the profit function of the distributor is

$$
\begin{aligned}
\pi_{d}(q)= & \theta_{1}\left[p S(q)-w(q-S(q))-e_{d}(\mu-S(q))\right]- \\
& -\left(c_{d}+p_{f}\right) q .
\end{aligned}
$$

The profit function of the refinery factory is:

$$
\begin{aligned}
\pi_{f}(q)= & \theta_{2}\left\{\left(1-\theta_{1}\right)[(p S(q)-w(q-S(q))-\right. \\
& \left.\left.-e_{d}(\mu-S(q))\right]+p_{f} q-e_{f}(\mu-S(q))\right\}- \\
& -\left(c_{f}+p_{r}\right) q
\end{aligned}
$$

The profit function of the recycling station is:

$$
\begin{aligned}
\pi_{r}(q)= & \left(1-\theta_{2}\right)\left\{\left(1-\theta_{1}\right)[p S(q)-w(q-S(q))-\right. \\
& \left.\left.-e_{d}(\mu-S(q))\right]+p_{f} q-e_{f}(\mu-S(q))\right\} \\
& =p_{r} q-c_{r} q-e_{r}(\mu-S(q))
\end{aligned}
$$

As calculated in the former, the profit function of the entire supply chain is:

$$
\pi(q)=(p+w+e) S(q)-(c+w) q-e \mu
$$

When $p_{f}, p_{r}$ meet the following conditions:

$$
\begin{aligned}
& p_{f}=\theta_{1} c-c_{d}+\theta_{1} \frac{\left(e_{f}+e_{r}\right)}{q}(\mu-S(q)) \\
& p_{r}=\theta_{2} c_{f}-\theta_{2} c_{r}-c_{f}+\theta_{2} \frac{e_{r}}{q}(\mu-S(q))
\end{aligned}
$$

Then, there will be $\pi_{d}(q)=\theta_{1} \pi(q), \pi_{f}(q)=\theta_{2}\left(1-\theta_{1}\right) \pi(q)$, $\pi_{r}(q)=\left(1-\theta_{2}\right)\left(1-\theta_{1}\right) \pi(q)$.

That is to say, under the revenue sharing contract, the profit function of the distributor, the refinery factory and the recycling station is the affine function of the entire supply chain system. Therefore, the optimal order quantity $\bar{q}$ of the system is unique. For the profit function of the supply chain system, $\pi(q)$ is concave function $(\pi(q)=-(p+w+e) f(q)<0)$ due to $\mathrm{F}$ which is strictly increased. Here,

$$
\bar{F}(\bar{q})=\frac{c+w}{p+w+e}
$$

\section{BIODIESEL SUPPLY CHAIN MODEL BUILDING UNDER DISTURBANCE SITUATION}

\subsection{Model building}

For the deterministic supply chain, the recycling station and the refinery factory obtained the optimal order quantity by forecasting the demand of the distributor, and arranged the production plan. At this point, due to some events like the government policy and other unexpected events, the random demand of the distributor is changed from $D$ to $G$. The recycling costs from the recycling station change from $c_{r}$ to $c_{r}+\Delta c_{r}$. Obviously, $c_{r}+\Delta c_{r}>0$. According to the practical significance, the distributor's new probability density function of $\mathrm{G}$ is $g(x)$, the distributor's new probability density function is $G(x)$. $\mathrm{G}$ also meets this condition that it is differentiable and strictly increasing. $\mathrm{G}(0)=0$, $\bar{G}(x)=1-G(x), \mu_{G}=E(G)$ is expected demand.

At this time, the expected sales volume of the distributor is:

$S_{G}(q)=q-\int_{0}^{q} G(y) d y$

Expected remaining quantity is:

$I_{G}(q)=q-S_{G}(q)$

Expected quantity of short supply is:

$L_{G}(q)=\mu_{G}-S_{G}(q)$

At this point, the profit function of the supply chain under disturbance situation becomes:

$$
\begin{aligned}
\prod(q)= & (p+w+e) S_{G}(q)-\left(c+\Delta c_{r}+w\right) q- \\
& -e \mu_{G}-\phi_{1}(q-\bar{q})^{+}-\phi_{2}(\bar{q}-q)^{+}, \\
& \phi_{1}, \phi_{2}>0
\end{aligned}
$$

In this formula, $\phi_{1}(q-\bar{q})^{+}$and $\phi_{2}(\bar{q}-q)^{+}$are additional costs incurred as a result of breaking the original plan. In case of a new order quantity $q>\bar{q}$, there is a need to reuse the new recycled raw material like waste cooking oil. There is $\phi_{1}$ which is an increase unit cost as a result of this; in case of the new order quantity $q<\bar{q}$, extra unit product needs to be done with some extra work like oil-water separation, storage and other processes. The $\phi_{2}$ is an additional cost for this work. In the real case study, $0<\phi_{2}<c+\Delta c_{r}$.

Unexpected events may cause the size of the market to increase or decrease, that is, for any $q \geq 0$, $\bar{G}(q) \geq \bar{F}(q)$ or $\bar{G}(q) \leq \bar{F}(q)$. Next, we will first consider the effect on supply chain optimal order quantity caused by simultaneous disturbance of market size and the recovery cost. Suppose the optimal order quantity is $q^{*}, q^{*}=\arg \max _{q \geq 0} \prod(q)$.

Theorem 1: If the recovery cost satisfies $-c<\Delta c_{r} \leq \phi_{2}$ and the market size increases, which is $\bar{G}(q) \geq \bar{F}(q)$ for $q \geq 0$, then $q^{*} \geq \bar{q}$, here, after the expansion of the demand expansion, the cost of change is negative, because of the economies of scale, the cost of recycling is smaller; if the recovery cost satisfies $\Delta c_{\underline{r}} \geq-\phi_{1}$ and the market size decreases, which is $\bar{G}(q) \leq \bar{F}(q)$ for $q \geq 0$, then $q^{*} \leq \bar{q}$. 
Proofing process: Assume $q^{*} \leq \bar{q}$ when the market demand increases in the event of uncertainty and the recovery cost changes in the range of $\left(-c, \phi_{2}\right]$, then the sufficient and necessary conditions for that $q^{*}$ is the solution of Equation 13 is $q^{*} \arg \max _{q \geq 0} \prod(q)$.

$$
\begin{aligned}
\hat{\prod}(q)= & (p+w+e)^{*} S_{G}(q)-\left(c+\Delta c_{r}+w\right)^{*} q- \\
& -e^{*} \mu_{G}-\phi_{2}(\bar{q}-q)
\end{aligned}
$$

Thus we can get the second derivative of $\hat{\prod}(q)$ $\hat{\prod}^{\prime \prime}(q)=-(p+w+e)^{*} g(q)<0$

So, $\hat{\prod}(q)$ is a strictly concave function. The sufficient and necessary conditions are that $q^{*}$ is the optimal solution of $\hat{\prod}(q)$ and that $q^{*}$ meets the following conditions $\hat{\prod}^{\prime}(q)=(p+w+e)^{*}(1-G(q))-\left(c+\Delta c_{r}+w\right)$ $+\phi_{2}=0$, which is equal to

$\bar{G}\left(q^{*}\right)=\frac{c+\Delta c_{r}+w-\phi_{2}}{p+w+e}$

For any $q \geq 0$, if the market demand increases due to unexpected events, there exist $\bar{G}(q) \geq \bar{F}(q)$. Then, because $\bar{G}(q)$ is a strictly decreasing function and $q^{*}<\bar{q}$ is supposed, there exist $\bar{G}\left(q^{*}\right)>\bar{F}(\bar{q})$. Thus $\bar{G}\left(q^{*}\right)=\frac{c+\Delta c_{r}+w-\phi_{2}}{p+w+e}>\frac{c+w}{p+w+e}=\bar{F}(\bar{q})$ is obtained. At the same time, because $-c<\Delta c_{r} \leq \phi_{2}$ and $\phi_{2}>0$, we know this is a contradictory conclusion. Therefore, when the recovery cost changes in $\left(-c, \phi_{2}\right]$, with the demand of the market becoming larger, the optimal output of the biodiesel supply chain should be greater than the original optimal order quantity. Another conclusion can be proven as similar to this.

Next, the changes will be given in optimal order quantity under the condition of simultaneous disturbance in the market size and the recovery cost.

$$
q^{*}=\left\{\begin{array}{l}
q_{1}^{*} \text { when } q_{1}^{*} \geq \bar{q} \\
\bar{q} \text { when } q_{1}^{*}<\bar{q}<q_{2}^{*} \\
q_{2}^{*} \text { when } q_{1}^{*}<\bar{q} \text { and } q_{2}^{*} \leq \bar{q}
\end{array}\right.
$$

where:

$q_{1}^{*}$ is the solution of $\bar{G}\left(q_{1}^{*}\right)=\frac{c+\Delta c_{r}+w-\phi_{2}}{p+w+e}$

$q_{2}^{*}$ is the solution of $\bar{G}\left(q_{2}^{*}\right)=\frac{c+\Delta c_{r}+w-\phi_{2}}{p+w+e}$

Proofing process: if $q \geq \bar{q}$, the profit function of the supply chain becomes:

$$
\begin{aligned}
\prod_{1}(q)= & (p+w+e)^{*} S_{G}(q)-\left(c+\Delta c_{r}+w\right)^{*} q- \\
& -e^{*} \mu_{G}-\phi_{1}(q-\bar{q})
\end{aligned}
$$

Because $\prod_{1}^{*}(q)=-(p+w+e)^{*} g(q)<0, \prod_{1}(q)$ is a strictly concave function.

Suppose $q_{1}^{*}$ follows the conditions of $\prod_{1}(q)$ first order optimal or $\prod_{1}^{\prime}\left(q_{1}^{*}\right)=0$, we can get
$\bar{G}\left(q_{1}^{*}\right)=\frac{c+\Delta c_{r}+w+\phi_{1}}{p+w+e}$

Therefore, according to the first order derivative and the monotone property, if $q_{1}^{*} \geq \bar{q}$, then $q_{1}^{*}$ is the maximum value of $\prod_{1}(q)$. Here $q_{1}^{*}=\arg \max _{q \geq \bar{q}} \prod_{1}(q)$. If $0<q_{1}^{*}<\bar{q}$, then $\prod_{1}(q)$ is strictly decreasing within $[\bar{q},+\infty)$. So, $\bar{q}$ is the maximum value of $\prod_{1}(q), q=\arg \max _{q \geq \bar{q}} \prod_{1}(q)$. If $0 \leq q<\bar{q}$, the profit function of the supply chain becomes: $\prod_{2}(q)=(p+w+e)^{*} S_{G}(q)-\left(c+\Delta c_{r}+w\right)^{*} q-e^{*} \mu_{G}-\phi_{2}(\bar{q}-q)$ Its second derivative $\prod_{2}^{\prime \prime}(q)=-(p+w+e)^{*} g(q)<0$ then $\prod_{2}(q)$ is a strictly concave function of $q$. Its first derivative $\prod_{2}^{\prime \prime}(q)=-(p+w+e)^{*} \bar{G}(q)-\left(c+\Delta c_{r}+w\right)+\phi_{2}$, it can be known, $\prod_{2}^{\prime}(q)$ is also strictly decreasing.

From the above, it shows that the function first increases and then decreases. Suppose $q_{2}^{*}$ satisfies $\prod_{2}^{\prime}\left(q_{2}^{*}\right)=0$, then

$\bar{G}\left(q_{2}^{*}\right)=\frac{c+\Delta c_{r}+w-\phi_{2}}{p+w+e}$

According to the first order derivative and the monotonic nature, if $0<q_{2}^{*}<\bar{q}, q_{2}^{*}$ is the maximum value of $\prod_{2}(q)$; here $q_{2}^{*}=\arg \max _{0 \leq q<\bar{q}} \prod_{2}(q)$. If $q_{2}^{*}<\bar{q}, \prod_{2}(q)$ is strictly increasing within $[0, \bar{q}]$, so, $\bar{q}$ is the maximum value of $\prod_{2}(q)$, that is, $\bar{q}=\arg \max _{0 \leq q<\bar{q}} \prod_{2}(q)$. When $q_{1}^{*}>\bar{q}$, , the maximum point of $\prod(q)$ in $[\bar{q},+\infty)$ is $q_{1}^{*}$, while in $[0, \bar{q}]$ the maximum point is $\bar{q}$ not $q_{2}^{*}$. Because if it is $q_{2}^{*}, q_{2}^{*} \in[0, \bar{q}]$, then there exists $q_{2}^{*}<\bar{q}<q_{1}^{*}$ which contradicts with $q_{2}^{*}>q_{1}^{*}$. So, the maximum value of $\prod(q)$ must be one of $\prod\left(q_{1}^{*}\right)$ and $\prod(\bar{q})$. Obviously, $\prod\left(q_{1}^{*}\right) \geq \prod(\bar{q})$. So, when $q_{1}^{*} \geq \bar{q}, \prod(q)$ can get the maximum value when $q^{*}=q_{1}^{*}$. Other proofs are similar. In summary, if $q_{1}^{*}>\bar{q}$, then $q^{*}=q_{1}^{*}$; if $q_{1}^{*}<\bar{q}<q_{2}^{*}$, then $q^{*}=\bar{q}, q_{1}^{*}<\bar{q}$ if and $q_{2}^{*} \leq \bar{q}$, then $q^{*}=q_{2}^{*}$.

\subsection{Biodiesel supply chain coordination under disturbance}

When the occurrence of unexpected events leads to changes in the supply chain, then the key problem is how to adjust the parameters of the revenue sharing contract to coordinate the supply chain. Here we give the coordination mechanism of the supply chain under the simultaneous disturbance of the demand and the recovery cost. Suppose the adjusted contract parameters are $\left(\bar{p}_{f}, \bar{\theta}_{1}\right),\left(\bar{p}_{r}, \bar{\theta}_{2}\right)$ we can get the profit function for the distributor which is:

$$
\begin{aligned}
\bar{\pi}_{d}(q)= & \bar{\theta}_{1}\left[p S_{G}(q)-w\left(q-S_{G}(q)\right)-\right. \\
& \left.-e_{d}\left(\mu_{G}-S_{G}(q)\right)\right]-\left(c_{d}+\bar{p}_{f}\right) q
\end{aligned}
$$

The profit function of the refinery factory is:

$$
\begin{aligned}
\bar{\pi}_{f}(q)= & \bar{\theta}_{2}\left\{( 1 - \overline { \theta } _ { 1 } ) \left[\left(p S_{G}(q)-w\left(q-S_{G}(q)\right)-\right.\right.\right. \\
& \left.\left.-e_{d}\left(\mu_{G}-S_{G}(q)\right)\right]+\bar{p}_{f} q-e_{f}\left(\mu_{G}-S_{G}(q)\right)\right\}- \\
& -\left(e_{f}+\bar{p}_{r}\right) q=\bar{\theta}_{2}\left(1-\bar{\theta}_{1}\right) \prod(q)
\end{aligned}
$$

The profit function of the recycling station is: 


$$
\begin{aligned}
\bar{\pi}_{r}(q)= & \left(1-\bar{\theta}_{2}\right)\left\{( 1 - \overline { \theta } _ { 1 } ) \left[\left(p S_{G}(q)-w\left(q-S_{G}(q)\right)-\right.\right.\right. \\
& \left.\left.-e_{d}\left(\mu_{G}-S_{G}(q)\right)\right]+\bar{p}_{f} q-e_{f}\left(\mu_{G}-S_{G}(q)\right)\right\}- \\
& -\left(c_{r}+\Delta c_{r}\right) q+\bar{p}_{r} q-e_{r}\left(\mu_{G}-S_{G}(q)\right)= \\
= & \left(1-\bar{\theta}_{2}\right)\left(1-\bar{\theta}_{1}\right) \prod(q)
\end{aligned}
$$

The profit function of the supply chain under disturbance situation is $\prod(q)=(p+w+e) S_{G}(q)-\left(c+\Delta c_{r}+w\right) q-$

$$
-e \mu_{G}-\phi_{1}(q-\bar{q})^{+}-\phi_{2}(\bar{q}-q)^{+}, \phi_{1}, \phi_{2}>0 \text {. }
$$

When $\bar{p}_{f}, \bar{p}_{r}$ meet the following conditions:

$$
\begin{aligned}
\bar{p}_{f}= & \bar{\theta}_{1 c}+\bar{\theta}_{1} \Delta c_{r}-c_{d}+\bar{\theta}_{1} \frac{e_{f}+e_{r}}{q}\left(\mu_{G}-S_{G}(q)\right)+ \\
& +\bar{\theta}_{1} \frac{\phi_{1}(q-q)^{+}+\phi_{2}(q-q)^{+}}{q}
\end{aligned}
$$

$$
\begin{aligned}
& \bar{p}_{r}=\bar{\theta}_{2 c_{f}}+\bar{\theta}_{2} c_{r}+\bar{\theta}_{2} \Delta c_{r}-c_{f}+\bar{\theta}_{2} \frac{e_{r}}{q}\left(\mu_{G}-S_{G}(q)\right)+ \\
& +\bar{\theta}_{2} \frac{\phi_{1}(q-\bar{q})^{+}+\phi_{2}(\bar{q}-q)^{+}}{q}
\end{aligned}
$$

then, there will be $\bar{\pi}_{d}(q)=\bar{\theta}_{1} \prod(q), \bar{\pi}_{f}(q)=$ $=\bar{\theta}_{2}\left(1-\bar{\theta}_{1}\right) \prod(q), \bar{\pi}_{r}(q)=\left(1-\bar{\theta}_{2}\right)\left(1-\bar{\theta}_{1}\right) \pi(q)$.

\section{CASE STUDY}

Based on the background of the biodiesel supply chain of Jiangsu Yueda Kate New Energy Co. Ltd, this paper simplifies and extracts the biodiesel supply chain. Its supply chain consists of three parties, the recycling station, the refinery factory and the distributor. According to the preliminary market research, it is known that the market demand for the company's products are subject to the uniform distributor of [20,000 t, 25,000 t] [31]. The retail price of the biodiesel is $\mathrm{P}=7,000 \mathrm{RMB} / \mathrm{t}$ [32]. The recycling cost of the recycling station is $c_{r}=4,000 \mathrm{RMB} / \mathrm{t}$. The manufacturing cost of the refinery factory is $c_{f}=1,300$ $\mathrm{RMB} / \mathrm{t}$. The ordering cost of the distributor is $c_{d}=500$ $\mathrm{RMB} / \mathrm{t}$. The deterioration rate of the unit product is $2 \%$, then we calculate the deterioration cost which is $1,400 \mathrm{RMB} / \mathrm{t}$ [33]. If the product gets out of stock or remaining, it will bring an increase in carbon emissions to the recycling station, the refinery factory and the distributor. This paper uses the current carbon emissions trading value to transform the increasing quantity of carbon emissions into emission cost eventually. Based on the recent trading average value, 30 $\mathrm{RMB} / \mathrm{t}$ is set in this paper. Carbon emissions of the recycling station and the distributor are mainly concentrated in terms of transport. According to [34], the Pre-treatment carbon emissions from food waste are $12.6 \mathrm{~kg} \mathrm{CO} \mathrm{CO}_{2} \mathrm{eqv}$./t, The production of carbon emissions is $39.61 \mathrm{CO}_{2}$ eqv./MJ which is $1.465 \mathrm{t} \mathrm{CO}_{2} \mathrm{eqv}$./t; then, we can calculate $e_{r}=1.2 \mathrm{RMB} / \mathrm{kg}, e_{d}=2.26 \mathrm{RMB} /$ $\mathrm{kg}$. On-the-spot investigation provides the information that the company's production carbon emissions quota is $1.538 \mathrm{CO}_{2}$ eqv./t [35], Finally, we can calculate $e_{f}=46.14 \mathrm{RMB} / \mathrm{kg}$.

The occurrence of an uncertainty is considered, which leads to a simultaneous disturbance in the product's market demand and recycling cost. The distributor's demand is assumed to be $Y=X+\Delta \mu \sim(20,000+\Delta \mu$, $25,000+\Delta \mu)$ after the disturbance. The market demand changes in $\Delta \mu \in[-2,000,2,000]$. The recovery cost changes in $\Delta c_{r} \in(-200,200)$ and other factors do not change. If the disturbance results in an increase in the yield of the product which exceeds the original production plan $q$, there is need to pay for the additional recycling cost $\phi_{1}=1,000 \mathrm{RMB} / \mathrm{t}$. If the disturbance leads to a decrease in the yield of the product, there is need to pay for the processing cost of surplus products $\phi_{2}=500 \mathrm{RMB} / \mathrm{t}$. When the disturbance occurs, the supply chain has two coping strategies: first, it can choose to turn a blind eye to disturbance, do not take any measures, continue to perform the original signed revenue sharing contract. This is the original strategy. Another is applying the disruption management theory, taking the new operational strategy to achieve the supply chain coordination. This paper only discusses the situation of the supply chain dealing with the disturbance. According to the above data, MATLAB programming software 2012b was used to analyse and compare the order quantity and profits in the two strategies.

\subsection{Original strategy scenarios}

It is not difficult to see from Figure 2, when the uncertainty events lead to simultaneous disturbance in the market demand and the recovery cost, the supply chain's profit change is determined by the degree of the disturbance in the case of the original strategy. The changing relationship: when the market demand changes are fixed, the total profit of the supply chain increases with the reduction of recovery cost; when the change of recovery cost is fixed, the total profit of the supply chain shows a trend of increase with the increasing market demand. Moreover, when $\Delta \mu=2,000$ $\Delta c_{r}=-200$, or the magnitude of the recovery cost reduction and the market demand increase are the largest, the total profit of the supply chain is the largest. When $\Delta \mu=-2,000 \Delta c_{r}=200$, or the magnitude of the recovery cost increases and the market demand reduction is the largest, the total profit of the supply chain is the lowest.

Figure 2 also shows, under the disturbance of the market demand $\Delta \mu \in[-2,000,0]$ and the recovery cost $\Delta c_{r} \in(0,200)$, the use of the original strategy can make the total supply chain profits decrease. On the contrary, under the disturbance of the market demand 
Table 1 - Each critical point profit in original strategy scenarios

\begin{tabular}{||c|c|c|c||}
\hline & -200 & 0 & 200 \\
\hline \hline-2000 & $435,249,118$ & $430,589,918$ & $425,930,718$ \\
\hline 0 & $529,377,527$ & $524,718,327$ & $520,059,127$ \\
\hline 2000 & $623,505,937$ & $618,846,737$ & $614,187,537$ \\
\hline
\end{tabular}

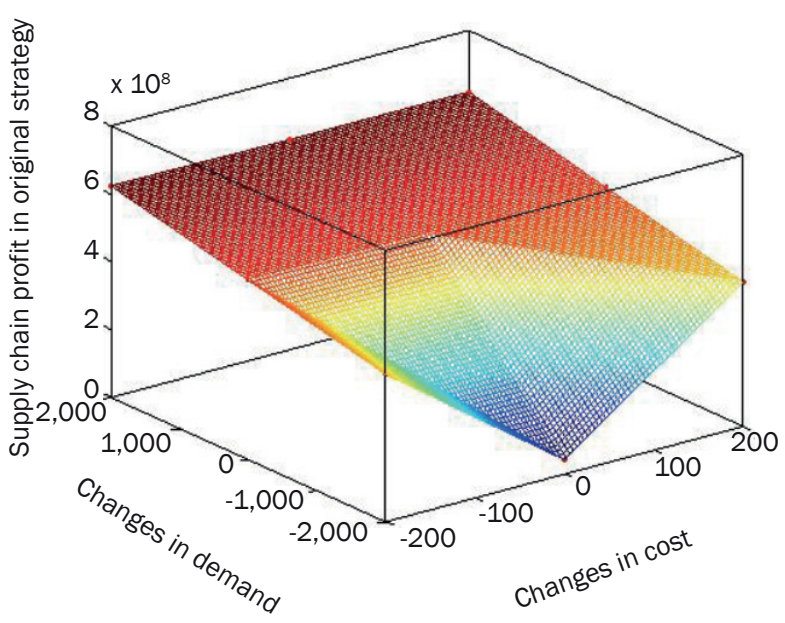

Figure 2 - Supply chain profit in the original strategy

$\Delta \mu \in[-2,000]$ and the recovery cost $\Delta c_{r} \in(0,200)$, the use of the original strategy can make the total supply chain profits increase.

After calculation, in the case of no disturbance, the optimal order quantity is 23,296 , and the profit of the supply chain is $524,718,327$. When the disturbance occurs, the profit at each critical point is shown in Table 1.

At the same time, as shown in Figure 2, it can be seen that the original strategy of the biodiesel supply chain is more noticeable by the relative cost disturbance.

\subsection{New strategy scenarios}

\subsubsection{The impact of the new strategy on optimal order quantity}

Figure 3 shows that the supply chain does not need to adjust the order quantity when the demand and cost disturbances are relatively small ( $\Delta \mu \in[-1,000,1,000]$, and $\left.\Delta c_{r} \in(-50,50)\right)$; all nodes can use the original optimal order quantity, and this does not need to change the production plan in the situation. When the demand and cost disturbances are relatively large, if the disturbance of the market demand is constant, the production of the supply chain increases with the decrease of production cost (when $\Delta c_{r} \geq 50$ or $\Delta c_{r} \leq-50$ ). If the cost of production is constant, the order quantity of the supply chain increases with the increase of the market demand $\Delta \mu \geq 1,000$ or $\Delta \mu \leq-1,000$

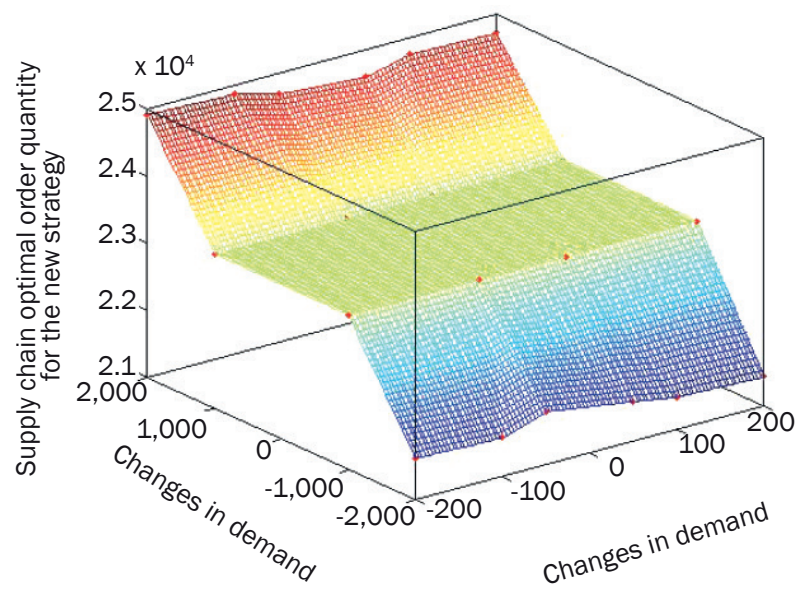

Figure 3 - Supply chain optimal order quantity for the new strategy

In the case of increased market demand and reduced production costs, when the demand disturbance is certain and the increase magnitude is larger, with the continuous reduction of production costs, the production planning adjustment also increases, and also the production increases; when the cost disturbance is certain and the reduction magnitude is larger, with the size of the market demand continuing to increase, the adjustment of the production plan also grows, increasing the production. Therefore, the new strategy under the supply chain needs to continue to increase the production.

In the case of reduced market demand and increased production costs, when the demand disturbance is certain and the reduction magnitude large, the adjustment of the production plan increases with the increasing production cost and the production decreases. When the cost perturbation is constant and the magnitude of the increase is large, the adjustment of the production plan increases with the decreasing demand of the market, and the production capacity decreases. 

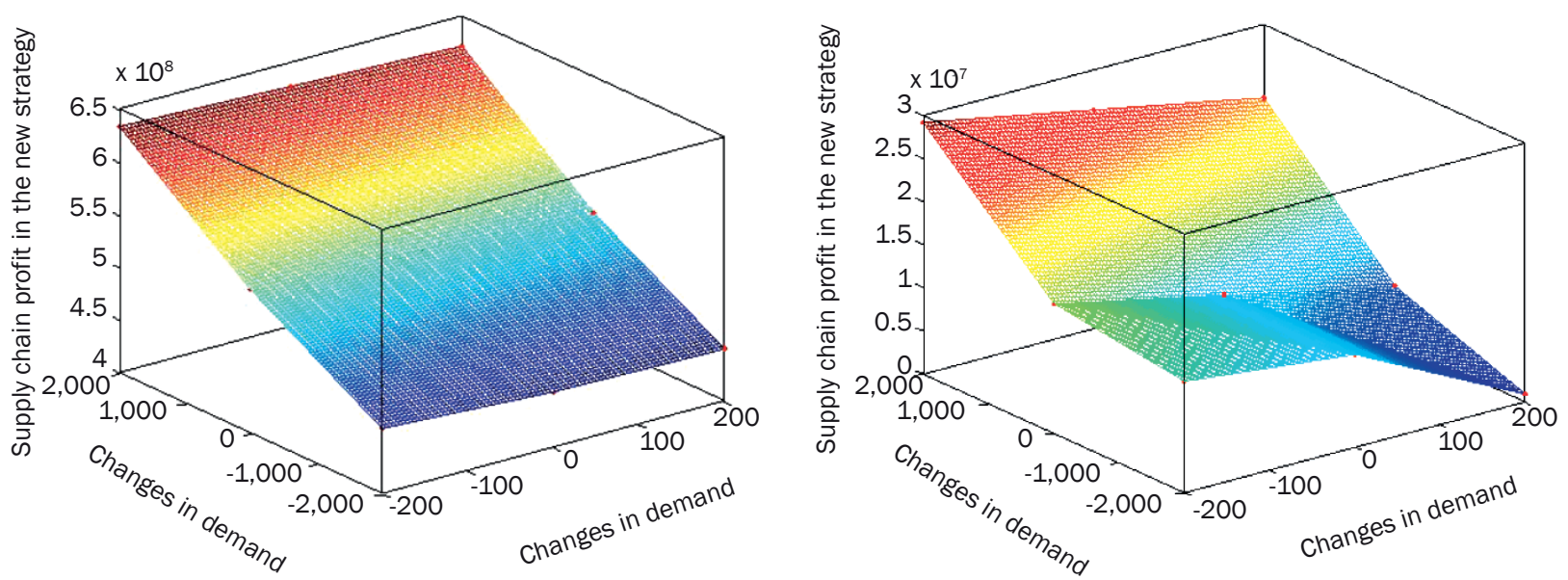

Figure 4 - Supply chain profit in the new strategy

\subsubsection{The impact of the new strategy on the supply chain profit}

The analysis results in Figure 4 are shown as follows:

1) The profit change of the supply chain is determined by disturbances of the market demand and the recovery cost;

2) When the market demand is constant, the profitability of the supply chain is inversely proportional to the change in recycling costs, which increases as the recycling costs decrease. This is because the cost is reduced, on the one hand the order of the entire supply chain features generally an increasing trend; on the other hand, the entire supply chain profit per unit also increased, so the entire supply chain benefits increase.

\subsection{Comparative analysis of the two strategies}

According to Figure 5, it shows that the profit difference between the new strategy and original strategy is non-negative. It shows that the biodiesel supply chain can improve the total profit of the supply chain until a

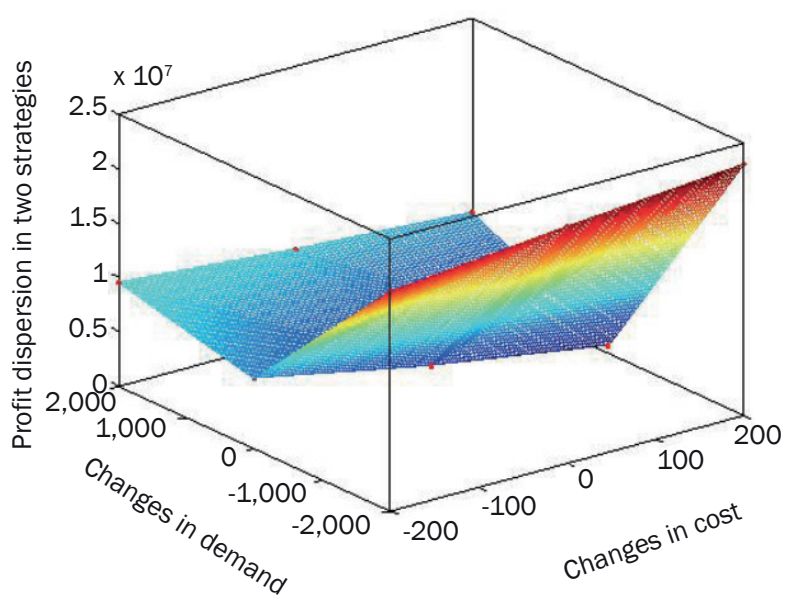

Figure 5 - Profit dispersion in the two strategies new strategy. The new strategy is better than the original strategy when the three parties are adjusted by contract under disturbance.

When $\Delta \mu=-2,000, \Delta c_{r}=-200$ and $\Delta \mu=-2,000$, $\Delta c_{r}=200$, the profit difference is the largest, which shows that the greater the disturbance, the more obvious advantages of the new strategy, and the profit is also higher after the new strategy adjustment. When $\Delta \mu=2,000, \Delta c_{r}=-200$ and $\Delta \mu=2,000, \Delta c_{r}=200$, the profit difference is still positive after single factor disturbance and is second only to the highest value. The advantage of the new strategy is still obvious. After new coordination, the profit is higher than the original strategy. When $\Delta \mu=0, \Delta c_{r}=0$ or there is no disturbance, the profit difference is positive, but the value is the smallest.

This shows that there is no obvious advantage of the new strategy in the absence of disturbance, and there is not much difference between the new strategy and the original strategy.

\section{CONCLUSION}

Due to the influence of raw materials on particularity and the external policy environment, the biodiesel market uncertainty is particularly evident. Market environment supply chain is becoming more complex and changeable. Therefore, all parties in the biodiesel supply chain need to take reasonable countermeasures to deal with uncertain situation.

This paper considers the coordination of biodiesel three-echelon supply chain based on a revenue sharing contract. Firstly, the optimal order quantity and the parameters of the contract under a certain situation are given in this paper. Then, when both the market demand and recovery cost change, it is analysed how to cope with disturbance, and give the changing contract parameters after disturbance. Finally, the real cases and data from Jiangsu Carter new energy Co., Ltd are taken, and MATLAB is used to carry out the analysis of 
the two strategies. According to the case results, when the market demand and recovery cost are disturbed, the coordination of the biodiesel three-echelon supply chain is robust, and the new strategy is better than the original one. Although the new strategy proposed in this paper has some help to improve the supply chain profit and deal with the disturbance, there are still some limitations and need for future research:

1) This paper considers a simple single-chain supply chain structure, but in real life, a one-to-many or many-to-many network supply chains are more common, which can study the multi-stage complex network supply chain.

2) The study of this paper is based on the assumption that the supply chain members are risk-neutral and information symmetry of the premise of the information asymmetry or incomplete situation can be used as a further study in this direction.

3) This paper discusses the market demand and recovery costs at the same time perturbed. What can be discussed next are the storage costs, service costs, lead time and other disturbances.

\section{ACKNOWLEDGEMENTS}

We would like to thank Prof. Yinsu Chen from the University of California Santa Cruz for his patient guidance, and valuable suggestions throughout the work of biofuel market analysis model.

This work was supported by the National Natural Science Foundation of China (Project No.: 71372198), Science and Technology Department of Jiangsu Province of China (Project No.: BY2015070-25), Nanjing Housing and Construction Commission (Project No.: Ks1513). We are grateful for valuable suggestions for improvement from these colleagues.

\author{
耿娜娜, 通讯作者, 东南大学博士研究生在读 \\ 中国江苏省南京市四牌楼 2 号 \\ 邮箱: shiyu0618@163.com \\ 张永, 东南大学副教授, 博士。 \\ 中国江苏省南京市四牌楼 2 号 \\ 邮箱: zhangyong@seu.edu.cn \\ 孙益祥, 南京航空航天大学博士研究生在读 \\ 中国江苏南京将军大道29号 \\ 邮箱: sunyixiang@nuaa.edu.cn
}

\section{基于收益共享契约法的扰动下生物燃料供应链协调 策略}

\section{摘要}

生物燃料被视为未来交通运输中的重要替代能源, 尽 管其发展得到了世界各国的支持，但是，生物燃料产业发 展仍然非常缓慢。从以往的研究来看, 我们知道需要解决 供应链协调等问题来提升供应链能力。本文从扰动管理的 角度研究生物柴油供应链协调问题。给出了一个包含最优 订货量和合同参数的扰动协调策略。然后, 运用江苏悦达 凯特新能源有限公司的实际数据, 对该协调策略进行了验
证。结果表明: 当市场需求和回收成本同时受到扰动时, 该协调策略可以使生物柴油供应链更具有鲁棒性, 利润共 享契约下的新策略要好于原策略。

关键词

废弃油, 碳排放, 扰动, 利润共享契约, 生物燃料供应链

\section{REFERENCES}

[1] Fatih Birol. World Energy Outlook. International Energy Agency; 2007.

[2] Ramos TRP, Gomes MI, Barbosa-Póvoa AP. Planning waste cooking oil collection systems. Waste Management. 2013;33(8): 1691-1703.

[3] Demirbas A. Importance of biodiesel as transportation fuel. Energy Policy. 2007;35(9): 4661-4670.

[4] Sana SS. Optimal contract strategies for two stage supply chain. Economic Modelling. 2013;30(1): 253-260.

[5] Zegordi SH, Abadi IK, Nia MB. A novel genetic algorithm for solving production and transportation scheduling in a two-stage supply chain. Computers \& Industrial Engineering. 2010;58(3): 373-381.

[6] Toktaş-Palut P, Ülengin F. Coordination in a two-stage capacitated supply chain with multiple suppliers. European Journal of Operational Research. 2010;212(1): 43-53.

[7] Ma P, Wang H, Shang J. Contract design for two-stage supply chain coordination: Integrating manufacturer-quality and retailer-marketing efforts. International Journal of Production Economics. 2013;146(2): 745-755.

[8] Jaber MY, Osman IH. Coordinating a two-level supply chain with delay in payments and profit sharing. Computers \& Industrial Engineering. 2006;50(4): 385-400.

[9] Ertek G, Griffin PM. Supplier-and buyer-driven channels in a two-stage supply chain. IEEE Transactions. 2002;34(8): 691-700.

[10] Munson CL, Rosenblatt MJ. Coordinating a three-level supply chain with quantity discounts. IEEE Transactions. 2001;33(5): 371-384.

[11] Hu JS, Wang H. The Price Discount Contract Analysis of Three- Level Supply Chain Under Disruption. Chinese Journal of Management Science. 2007;15(3): 103-107.

[12] Modak NM, Panda S, Sana SS. Three-echelon supply chain coordination considering duopolistic retailers with perfect quality products. International Journal of Production Economics. 2016;182: 564-578.

[13] Panda S, Modak NM, Basu M. Disposal cost sharing and bargaining for coordination and profit division in a three-echelon supply chain. International Journal of Management Science and Engineering Management. 2014;9(4): 276-285.

[14] Govindan K, Popiuc MN. Reverse supply chain coordination by revenue sharing contract: A case for the personal computers industry. European Journal of Operational Research. 2014;233(2): 326-336.

[15] Razmi J, Moghadam AT, Jolai F. An Evaluative Continuous Time Markov Chain Model for a Three Echelon Supply Chain with Stochastic Demand and Lead Time. IFAC-Papers OnLine. 2015;48(3): 248-253.

[16] Cárdenas-Barrón LE, Treviño-Garza G. An optimal solution to a three echelon supply chain network with multi-product and multi-period. Applied Mathematical 
Modelling. 2014;38(5): 1911-1918.

[17] Shankar BL, Basavarajappa S, Chen JC, Kadadevaramath RS. Location and allocation decisions for multi-echelon supply chain network - A multi-objective evolutionary approach. Expert Systems with Applications. 2013;40(2): 551-562.

[18] Awudu I, Zhang J. Uncertainties and sustainability concepts in biofuel supply chain management: A review. Renewable and Sustainable Energy Reviews. 2012;16(2): 1359-1368.

[19] Rajagopal D, Plevin RJ. Implications of market-mediated emissions and uncertainty for biofuel policies. Energy Policy. 2013;56: 75-82.

[20] Markel E, Sims C, English BC. Examining the effects of uncertainty on second-generation biofuel investment by using a two stochastic process approach. $2016 \mathrm{An}$ nual Meeting, July 31-August 2, 2016, Boston, Massachusetts (No. 235827). Agricultural and Applied Economics Association; 2016.

[21] Rozakis S, Sourie JC. Micro-economic modelling of biofuel system in France to determine tax exemption policy under uncertainty. Energy Policy. 2005;33(2): 171-182.

[22] Akgul O, Shah N, Papageorgiou LG. Economic optimisation of a UK advanced biofuel supply chain. Biomass and Bioenergy. 2012;41: 57-72.

[23] Qureshi N, Saha BC, Cotta MA, Singh V. An economic evaluation of biological conversion of wheat straw to butanol: a biofuel. Energy Conversion and Management. 2013;65: 456-462.

[24] Hill J, Nelson E, Tilman D, Polasky S, Tiffany D. Environmental, economic, and energetic costs and benefits of biodiesel and ethanol biofuels. Proceedings of the National Academy of Sciences. 2006;103(30): 11206-11210.

[25] Hill J. Environmental costs and benefits of transportation biofuel production from food-and lignocellulose-based energy crops. A review. Agronomy for Sustainable Development. 2007;27(1): 1-12.
[26] Demirbas A. Political, economic and environmental impacts of biofuels: a review. Applied Energy. 2009;86: S108-S117.

[27] Kou N, Zhao F. Techno-economic analysis of a thermo-chemical biofuel plant with feedstock and product flexibility under external disturbances. Energy. 2011;36(12): 6745-6752.

[28] Awudu I, Zhang J. Stochastic production planning for a biofuel supply chain under demand and price uncertainties. Applied Energy. 2013;103: 189-196.

[29] Yue D, You F. Fair profit allocation in supply chain optimization with transfer price and revenue sharing: MINLP model and algorithm for cellulosic biofuel supply chains. AlChE Journal. 2014;60(9): 3211-3229.

[30] Kumarappan S. Biomass supply chains for biofuel production-Contracting issues. In: Sixth Annual World Congress on Industrial Biotechnology \& Bioprocessing, 14 Jul 2009, Montreal, Canada; 2009.

[31] Dal-Mas M, Giarola S, Zamboni A, Bezzo F. Strategic design and investment capacity planning of the ethanol supply chain under price uncertainty. Biomass and Bioenergy. 2011;35(5): 2059-2071.

[32] Mapemba LD, Epplin FM, Huhnke RL, Taliaferro CM. Herbaceous plant biomass harvest and delivery cost with harvest segmented by month and number of harvest machines endogenously determined. Biomass and Bioenergy. 2008;32(11): 1016-1027.

[33] Zhang Y, and Jiang Y. Robust optimization on sustainable biodiesel supply chain produced from waste cooking oil under price uncertainty. Waste Management. 2017;60: 329-339.

[34] Jiang B, Li J, Mao X. Container ports multimodal transport in China from the view of low carbon. The Asian Journal of Shipping and Logistics. 2012;28(3): 321-343.

[35] Ou X, Zhang X, Chang S, Guo Q. Energy consumption and GHG emissions of six biofuel pathways by LCA in (the) People's Republic of China. Applied Energy. 2009;86: S197-S2 